\title{
MIDAS
}

Museus e estudos interdisciplinares

$11 \mid 2020$

Dossier temático: "Perspetivas sobre o museu eclético"

\section{The Art of Collecting [exposição]}

\section{Susana S. Martins}

\section{(2) OpenEdition \\ Journals}

Edição electrónica

URL: http://journals.openedition.org/midas/1658

DOI: $10.4000 /$ midas. 1658

ISSN: 2182-9543

\section{Editora:}

Alice Semedo, Paulo Simões Rodrigues, Pedro Casaleiro, Raquel Henriques da Silva, Ana Carvalho

\section{Refêrencia eletrónica}

Susana S. Martins, "The Art of Collecting [exposição] », MIDAS [Online], 11 | 2020, posto online no dia 19 novembro 2020, consultado no dia 21 novembro 2020. URL : http://journals.openedition.org/ midas/1658; DOI : https://doi.org/10.4000/midas.1658

Este documento foi criado de forma automática no dia 21 novembro 2020

\section{(c) (i) (3) (2)}

Midas is licensed under a Creative Commons Attribution-NonCommercial-ShareAlike 3.0 International License 


\section{The Art of Collecting [exposição]}

\section{Susana S. Martins}

\section{REFERÊNCIA}

The Art of Collecting. 2017. Exposição patente no M-Museum Leuven, Lovaina, Bélgica, entre 11 de junho de 2017 e 19 de abril de 2020.

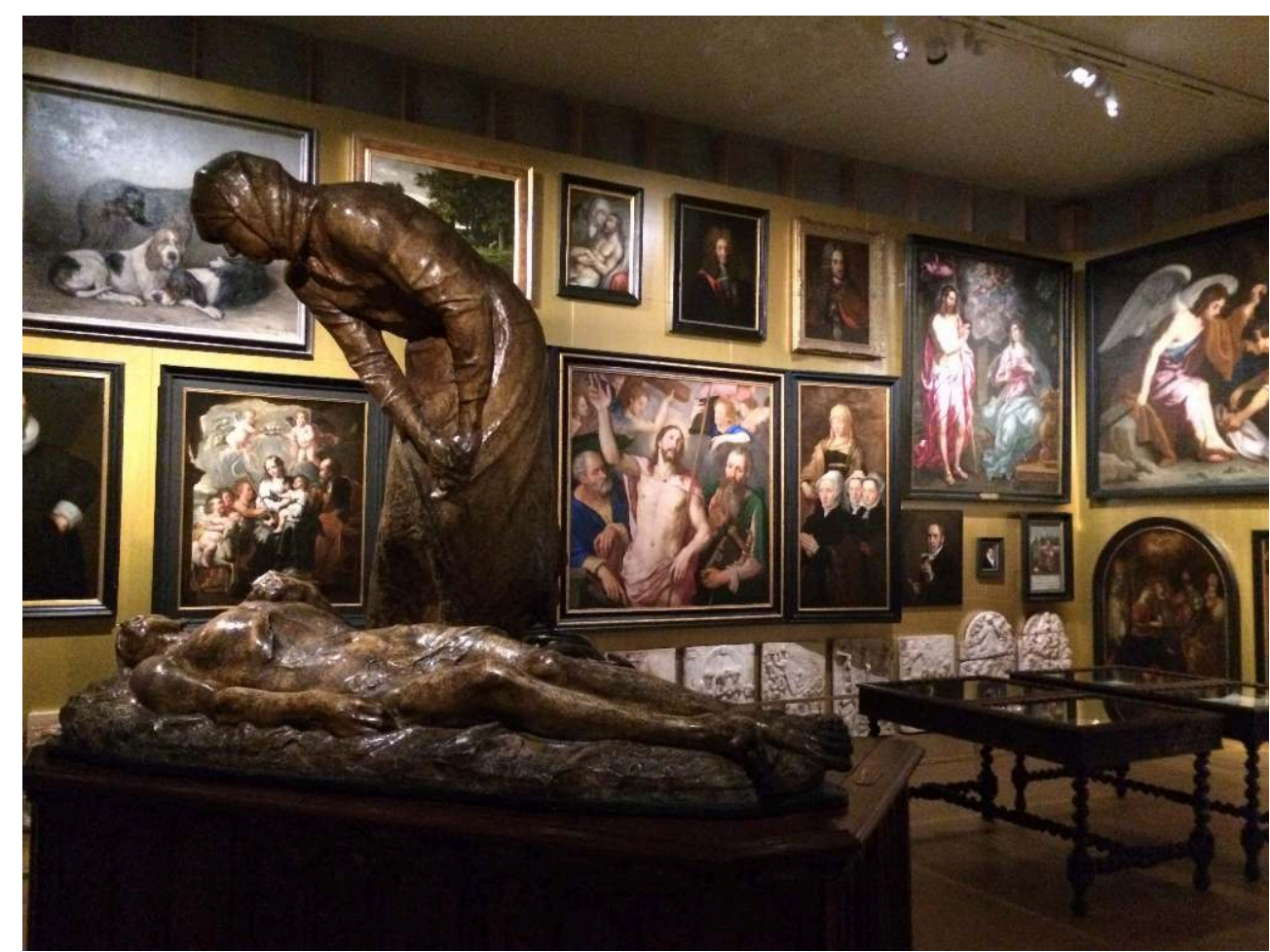

Exposição The Art of Collecting, 2018, M-Museum Leuven, Bélgica (c) Susana S. Martins 
1 O conceito de "coleccionar" é tão vasto, antigo e complexo que poderia, facilmente, ocupar muitos e inesgotáveis museus. ${ }^{1}$ Não é isso que acontece na cidade de Lovaina, onde a exposição The Art of Collecting (Verzameling is een Kunst) se desdobra espantosamente apenas numa pequena ala do M-Museum Leuven (daqui em diante MMuseum). Felizmente, a amplitude espacial e física de uma exposição não tem necessária correspondência na dimensão das questões que ela pode porventura colocar. E é precisamente isso que acontece nesta mostra: a exposição A Arte de Coleccionar é aparentemente pequena, mas a sua ambição e alcance, enormes.

2 Importará, em primeiro lugar, referir que o tema da colecção não é, aqui, tratado de forma antológica. Não se pretendeu fazer um levantamento completo de formas e tipologias de colecção, nem tão pouco traçar um percurso linear das práticas coleccionistas, desde as suas origens pré-históricas até aos dias de hoje. Trata-se antes de reflectir sobre a ideia de colecção através de uma abordagem que, sendo bastante abrangente e polissémica, é sempre pensada a partir da sua relação com o dispositivo do próprio museu. Ao percorrer os vários sentidos e implicações que a referida "arte de coleccionar" pode então assumir em contexto institucional, a exposição cumpre um duplo propósito: o de, por um lado, revisitar diferentes momentos da história particular do museu e, por outro, o de elaborar uma crítica mais geral acerca do modo - nunca neutro - como os museus escolhem apresentar as suas colecções.

3 As colecções museológicas nem sempre são organismos simples. Na verdade, os museus têm frequentemente de lidar e trabalhar com colecções que contam com séculos de existência e que foram motivadas por razões já muito distantes da sensibilidade contemporânea. Esse é também um dos grandes desafios com que se depara o MMuseum, um museu que, continuando a expandir a sua colecção em estreito diálogo com a produção artística contemporânea, tem ao mesmo tempo de lidar com o legado das suas colecções originais e, consequentemente, com o eclectismo de um património histórico extenso, que pré-existe à constituição propriamente dita do museu, cuja última reinauguração data de 2009.

4 Esta diversidade (e dificuldade) da colecção, está desde logo plasmada no início da exposição. Apesar de toda a mostra se organizar numa cronologia não sequencial, feita de avanços e recuos, é na primeira sala que este aspecto se torna mais evidente, se não mesmo contrastante. O núcleo inaugural começa por dar voz a uma série de coleccionadores contemporâneos: nele se reúnem ao mesmo tempo peças representativas das suas colecções e entrevistas que, de alguma forma, abrem portas para um particular território psicológico. No mesmo espaço, porém, e num segundo momento, o visitante é convidado a transitar na obscuridade para a outra extremidade da linha do tempo - para uma espécie de gabinete de curiosidades (que evoca o original do século XVIII), onde estão expostas algumas das mais antigas obras da colecção do museu. $\mathrm{O}$ dramatismo da iluminação destas peças acentua a sua condição de tesouros, todos eles ligados à história da cidade: e é assim, nessa atmosfera de maravilhamento, que se descobrem códices iluminados, um pergaminho de 1505 com o projecto nunca executado da torre da igreja de Sint-Pieters, ou uma desproporcionada e interpeladora cabeça feminina, o único vestígio-relíquia da gigante Megera, figura recorrente de uma procissão secular que marcou a cidade de Lovaina do século XIV ao século XVII.

$5 \mathrm{Na}$ sala seguinte, mais ampla e mais iluminada, a viagem temporal prossegue, e avançamos quase 100 anos. Num dos momentos mais estimulantes da exposição, recriase o que seria o aspecto da galeria municipal, o espaço antecessor do museu, e o modo 
como nela se apresentavam as obras por volta de 1900. Para tal, oferece-se ao visitante um espectáculo museográfico particular: um acumular de obras, do chão ao tecto, em que praticamente nenhum centímetro é desperdiçado. Para além de dar a ver um modelo expositivo fino-oitocentista, o que este núcleo mais notavelmente recria é a própria "experiência" - sensorial e perceptiva - do que seria a exposição nesses anos. Essa experiência é levada quase ao limite, na medida em que não se fornece qualquer informação sobre cada uma das obras: anónimos, amadores, e mestres convivem sem a hierarquia dos nomes, das tabelas, dos períodos. Sem dados ou notas explicativas e, mais ainda, sem uma voz que faça sentido da história que ali se conta, apenas um olhar mais educado saberá distinguir as ditas obras-primas dos objectos artísticos menos consagrados pela historiografia. Curiosamente, porém, a ausência de discurso ou de orientação abre espaço para um outro tipo de fruição. 0 visitante pode aproximar-se desta saturação expositiva, ficar a centímetros das obras, numa espécie de corpo a corpo em que é permanentemente desafiado pelos olhares dos retratados, pela atracção quase física dos detalhes imprevistos, pela materialidade da própria arte. E, naturalmente, pelos limites do seu próprio conhecimento.

Tal recriação da máquina expositiva do final do século XIX configura uma espécie de "exposição de exposição", onde inclusivamente se apresentam as fontes fotográficas (os centenários postais ilustrados, inicialmente comercializados ao público no próprio museu municipal e agora dispostos numa vitrine de época) que permitiram o processo de reconstituição da feição original da galeria, na qual a acumulação de obras na parede se deve, em parte, aos códigos salonistas, e em parte, ao facto de o museu ser, à época, detentor de uma colecção mais reduzida e não possuir ainda qualquer tipo de reservas ou espaço de armazenamento.

7 A comprometida incursão que o M-Museum realiza sobre a sua própria pré-história parece surgir em plena sintonia com o movimento revisionista que nos últimos anos tem marcado profundamente as práticas, as instituições e os estudos de museus. Da reencenação de exposições notáveis, ao lançamento de catálogos raisonnés de exposições, ou à concepção de arquivos digitais e multimédia, um pouco por toda a parte as instituições museológicas têm vindo a assumir um posicionamento historiográfico importante, através do qual têm revisitado o passado e elaborado uma reflexão (mais ou menos crítica, mais ou menos auto-celebratória) sobre as suas heranças artísticas e expositivas.

8 Mas esta exposição tem algo de particularmente audacioso no modo como dessacraliza e humaniza o espaço e a função do museu. Uma linha democratizante trespassa o circuito a vários níveis. Os coleccionadores, por exemplo, não são apresentados como figuras intangíveis ou difíceis de igualar. Por sua vez, o discurso que acompanha a exposição faz uma tentativa de envolver o visitante e de o colocar ao mesmo nível da instituição museológica. De forma tão discutível como sugestiva, o texto de apresentação afirma mesmo: «Todos coleccionamos alguma coisa. Alguns coleccionam sapatos, outros fotografias em smartphones. E os museus coleccionam arte e património. É isso que têm em comum com os seus visitantes» (tradução da autora).

9 É de acordo com esta retórica de horizontalidade que ganha protagonismo nesta mostra, um momento de apelo directo à participação. Num grande ecrã táctil, convidase o visitante a assumir o papel de curador de museu: nesse dispositivo, as pessoas têm acesso a informação sobre cada uma das 90 obras expostas na sala, e podem, depois, experimentar reorganizar virtualmente a exposição, de acordo com os critérios 
museológicos que entenderem. A vertente lúdica desta interacção promove uma equiparação entre a equipa do museu e o público que dele frui, apresentando a tarefa curatorial como algo simples, ao alcance de um mero deslizar de dedos. Mas curiosamente, quem se dispõe a participar no jogo depressa se confronta - apesar de todas as facilidades do sistema (pesquisa por tema, período, etc.) - com a complexidade das escolhas, e naturalmente com a hesitação e a finitude das suas referências.

Esta interpelação repercute-se, pois, como uma revelação da dificuldade com que o próprio museu se depara: como expor uma colecção diversa, com mais de 50000 peças? A visita vai tornando evidente que qualquer exposição, começando por esta, corresponde afinal apenas a uma escolha, entre tantas outras possibilidades. $O$ núcleo final, composto por obras do final do século XIX e inícios do século XX, reforça bem essa ideia. Aqui se demonstra que mesmo uma composição museográfica depurada e alinhada com os protocolos que o paradigma modernista consolidou até hoje, implica sempre uma poderosa orientação (a exposição refere mesmo "manipulação") do olhar e da interpretação. Deste modo, a exposição faz mais do que apresentar a colecção do MMuseum; ela acentua como os diferentes modos de exposição que os museus optam por assumir têm uma derradeira influência na experiência estética e cultural que neles se promove, e no valor que se lhes atribui.

11 Talvez fiquem por explorar algumas questões relacionadas com o impacto que uma colecção, ou coleccionador, pode ter no seu tecido sócio-cultural, nomeadamente na sua relação como o mercado, com as instituições, com novos espaços e programas culturais, com a comunidade artística e com o público. Mas a problemática desta exposição é de uma outra ordem. Ao reflectir sobre a mutabilidade histórica dos modelos expositivos e sobre a forma como o museu se relaciona com os seus próprios legados, esta exposição arrisca não apenas na reflexão crítica e educativa que propõe, como também na forma original como expõe o papel e a voz do museu. Apesar da crescente abertura e transformação dos museus em espaços mais atentos e orientados para os seus diferentes públicos, a margem para contestar uma certa autoridade institucional e curatorial permanece reduzida. 0 que é mais invulgar nesta exposição é precisamente a adopção de um posicionamento institucional que recusa escudar-se numa autoridade abstracta e sem rosto, e que revela as pessoas, as hesitações e os condicionalismos por detrás da instituição e dos modos, sempre tão relativos, de fazer exposição e atribuir sentido. Dessa forma, esta exposição tem a coragem de, construtivamente, afirmar o museu não apenas como um laboratório de processos, mas sobretudo como um permanente território de dúvida e de vulnerabilidade.

\section{NOTAS}

1. A autora escreve de acordo com a antiga ortografia. 


\section{AUTORES}

\section{SUSANA S. MARTINS}

Instituto de História da Arte (IHA), Faculdade de Ciências Sociais e Humanidades da Universidade Nova de Lisboa, Portugal, smartinsiha@fcsh.unl.pt 